\title{
O ensino de Filosofia da Educação e as noções de bons encontros, acontecimento e superfície
}

\author{
The teaching of Philosophy of Education and the notions of good meetings, \\ event and surface
}

\section{Enseñanza de Filosofía de la Educación y las nociones del buenos encuentros, acontecimiento e y superficie}

FERNANDA MOTA*

\begin{abstract}
$\diamond$
RESUMO

Este trabalho tem por objetivo apresentar algumas considerações sobre as noções de bons encontros, acontecimento e superfície no âmbito da filosofia da educação. Trata-se de uma pesquisa de caráter bibliográfico, fundamentada na construção de conhecimentos oriundos das contribuições de autores contemporâneos, além de estudos posteriores feitos por estudiosos e pesquisadores sobre as ideias de tais autores. Esse procedimento é necessário porque nem todos os autores trataram sistematicamente do tema em questão, mas apenas abordaram-no esporadicamente em alguns textos. A fundamentação teórica baseia-se em autores como Scruton (2000), Deleuze e Guattari (2010), Deleuze (1992; 2002; 2011), Foucault (2014; 2012; 2012), Pagni (2010; 2011; 2012), dentre outros. Primeiramente, o estudo foca na descrição das três noções mencionadas para, em seguida, apresentar a mútua articulação entre essas noções. O estudo finaliza com a indicação de um caminho alternativo para o ensino da filosofia da educação a partir de uma abordagem combinada das noções de bons encontros, acontecimento e superfície.
\end{abstract}

Palavras-chave: Filosofia da Educação. Ensino. Bons encontros. Acontecimento. Superfície.

\begin{abstract}
This paper aims to present some considerations about the notions of good meetings, event and surface in the scope of philosophy of education. This is a bibliographic research, based on the construction of knowledge drawn from the contributions of contemporary authors, and later studies made by scholars and researchers on the ideas of such authors. This approach is necessary because not all authors treated the theme being studied systematically, but addressed it only sporadically in some texts. The theoretical foundation is based on authors such as Scruton (2000), Deleuze e Guattari (2010), Deleuze (1992, 2002, 2011), Foucault (2014, 2012, 2012), Pagni (2010; 2012; 2012) among others. First, the study focuses on the description of the three notions mentioned to then present the mutual articulation between these notions. The study ends with the indication of an alternative way to teach the philosophy of education from a combined approach of the notions of good meetings, event and surface.
\end{abstract}

Keywords: Philosophy of Education. Teaching. Good meetings. Event. Surface.

\section{RESUMEN}

Este trabajo tiene como objetivo presentar algunas reflexiones sobre las nociones del buenos encuentros, acontecimiento y superficie dentro de la filosofía de la educación. Se trata de una investigación bibliográfica, basado en la construcción del conocimiento a partir de las contribuciones de los escritores contemporáneos y estudios posteriores de estudiosos e investigadores sobre las ideas de estos autores. Esto es necesario porque no todos los autores abordan sistemáticamente el tema en cuestión, pero sólo se le acercaron esporádicamente en algunos textos. El marco teórico se basa en autores como Scruton (2000), Deleuze y Guattari (2010), Deleuze (1992, 2002, 2011), Foucault (2014, 2012, 2012), Pagni $(2010 ; 2012 ; 2012)$, entre otros. En primer lugar, el estudio se centra en la descripción de los tres conceptos mencionados para en seguida presentar la relación mutua entre estas nociones. El estudio concluye con la indicación de una ruta alternativa a la enseñanza de la filosofía de la educación desde un enfoque combinado de las nociones del buenos encuentros, acontecimiento y superficie.

Palabras clave: Filosofía de la Educación. Enseñanza. Buenos encuentros. Acontecimiento. Superficie.

\footnotetext{
* Doutora em Educação pela Universidade Federal do Piauí (UFPI). Professora adjunta de Filosofia da Educação na Universidade Federal do Piauí (UFPI). Centro de Ciências da Educação (CCE). Departamento de Fundamentos da Educação (DEFE). <https://orcid.org/0000-0001-5991-100X>. E-mail: <fabmota13@yahoo.com.br>.
} 


\section{INTRODUÇÃO}

A proposta deste artigo reside em abordar, a partir da leitura de Deleuze em sua obra Espinosa: Filosofia prática, a noção de bons encontros (e maus encontros), como um norteamento para a experiência educativa no âmbito do ensino de Filosofia da Educação. Essa perspectiva será articulada com outras noções deleuzianas, como o acontecimento e a arte da superfície e, posteriormente, também serão conectadas com a noção foucaultiana de cuidado de si, particularmente, no que concerne a paraskeué, a preparação do indivíduo para a sua existência.

A presença do filósofo francês contemporâneo Gilles Deleuze no Brasil como aporte teórico não é recente já que suas obras foram traduzidas e publicadas por editoras nacionais a partir dos anos de 1970. E nas três décadas subsequentes, uma vasta produção teórica e acadêmica foi produzida a partir de suas ideias (TADEU; KOHAN, 2005; GALLO, 2008; PAGNI, 2012).

Essa recepção constituída pelo olhar filosófico educacional, ao mesmo tempo, recupera alguns textos e introduz outros. No caso de Deleuze, embora muitos estudos tenham sido produzidos no campo educacional em torno de noções trabalhadas nas obras Diferença e repetição (2006), Mil platôs (1997) e O que é filosofia? (1992), a novidade reside na retomada de uma obra anterior: a Lógica do sentido (1982), especialmente, no que diz respeito às reverberações do legado filosófico cínico e estoico na contemporaneidade. Visto que excede o escopo deste trabalho apresentar um estudo pormenorizado acerca das referidas obras, eventuais menções às mesmas serão feitas na medida em que suas conexões se fizerem necessárias para elucidar a articulação entre as noções deleuzianas trabalhadas nesse artigo.

Tentaremos evidenciar que embora existam múltiplos caminhos a serem trilhados a partir das ideias de Deleuze, algumas conexões específicas serão necessárias (por exemplo, com os cínicos, os estoicos e o Foucault tardio) para que as trilhas percorridas sejam caracterizadas em conformidade com a noção de bons encontros e culminem na experiência formativa como arte da superfície. A esse respeito é importante notar que na acepção deleuziana, uma aula não deve ser sobre algo que já sabemos, mas sobre aquilo que buscamos: não se trata de reconhecer, mas de buscar novos encontros (DELEUZE, 1992). No caso de Foucault, trata-se mais de um desvelamento, representado pela exposição de sua faceta como professor, apresentada de forma ampla a partir da publicação de uma coletânea que reúne seus cursos, seminários, conferências, entrevistas e ensaios que propiciam "uma leitura renovada dos processos de formação humana" (FREITAS, 2012, p. 52). Isso porque, nessa fase denominada de estética da existência, Foucault aborda teorias relativas à formação humana em especial na educação. Assim, suas contribuições teóricas oferecem subsídios importantes para a pesquisa no campo da filosofia da educação e também na conceituação da noção de cuidado de si como uma alternativa ao conhecimento de si na relação entre professor e aluno, articulado com elementos da experiência docente.

Nos textos foucaultianos tardios somos advertidos que o cuidado de si, tal como havia sido praticado nas antigas sociedades gregas e romanas, foi perdido no decorrer do tempo sendo substituído pelo conhecimento de si. Para retomarmos o sentido do cuidado de si na contemporaneidade é fundamental termos consciência acerca de nossas competências, fraquezas e do que queremos. Precisamos fazer o exercício da análise da nossa própria consciência e julgamento do viver, do cuidar (FOUCAULT, 2012). Nesse contexto, as práticas ou ações sobre si (paraskeué) são compreendidas nos textos foucaultianos como uma forma através da qual o indivíduo pode vir a se modificar, se transformar. Assim, na acepção foucaultiana, a aula deveria priorizar a preparação do indivíduo para acontecimentos sobre os quais não se tem nenhum controle e que podem ou não ocorrer: em outras palavras, é preciso se preparar para o impreparável, num processo contínuo de preparação que faz o indivíduo se reinventar continuamente.

\section{OS BONS ENCONTROS E A CONTRAEFETUAÇÃO DO ACONTECIMENTO PARA HABITAR A SUPERFÍCIE}

O tema da arte da superfície é tratado prioritariamente na obra Lógica do Sentido (DELEUZE, 2011). Todavia, seu ressoar pode ser encontrado também na obra Espinosa: Filosofia Prática (DELEUZE, 2002). Sob o pretexto de explicitar uma característica da escrita de Espinosa, o filósofo francês menciona que o autor costumava desenvolver suas principais teses nas vulcânicas notas de rodapé de seus livros. Assim, se pretendemos evocar um ensino de Filosofia da Educação a partir das três imagens, a primeira exigência para o professor seria atentar para os seus limiares: suas alturas e suas profundezas. Habitar a superfície não significa negar as alturas celestiais e as profundezas vulcânicas, mas saber deslizar entre as mesmas.

Dessa forma, não devemos proceder como a águia de Platão que contempla as coisas a partir de uma perspectiva do alto e tampouco devemos agir como toupeiras que se escondem nos emaranhados túneis do subterrâneo. A opção deleuziana, evocada em três ocasiões, recai sobre a figura do carrapato que possui somente três afetos, sendo que dois deles são seus limiares (DELEUZE, 2011, p. 136; 
DELEUZE; GUATTARI, 2010, p. 219; DELEUZE, 2002, p. 129-130). Os afetos do carrapato são o da luminosidade, o olfativo e o calorífico. Pelo primeiro, ele sobe até o galho mais alto e lá permanece até o momento em que, sentindo o odor de algum mamífero, ele se deixa cair sobre as costas do animal que passa sob o galho. Em seguida, ele se deixa levar pela afetação do calor, em busca de regiões mais quentes e sem pêlos do animal. Em outros termos, poderíamos dizer que o carrapato usou suas sandálias aladas para se elevar até o cume da rama para, em seguida, habitar a superfície da pele do animal e que, depois, usou seu capacete da invisibilidade para se ocultar nas profundas pelagens.

Conforme Deleuze (2002), tudo o que precisamos é ter sempre em perspectiva nossos dois limiares, um limiar ótimo e um limiar péssimo que nos afetam. Essa noção baseia-se na concepção espinosista de que os modos de existência podem ser resumidos em dois tipos: bons ou maus. Aqui, a advertência é que tais noções não têm conotações moralizantes transcendentais, mas apenas sentidos modais e imanentes. Algo será considerado bom, forte ou razoável se contribuir para selecionar e organizar encontros que convém à nossa natureza e que, por apresentarem relações combináveis com outros elementos, aumentam a nossa potência de sermos afetados. Inversamente, será considerado mau, fraco ou insensato aquilo que vive à margem dos encontros, limitando-se a sofrer suas consequências e a lastimar a diminuição de sua potência conectiva de ser afetado.

O filósofo francês explica ainda que Espinosa denomina, respectivamente, de alegria e tristeza as afetações sentidas pelos nossos corpos quando encontramos outros corpos ou ideias, numa relação que se compõe para formar um todo mais potente (isto é, com mais capacidade de estabelecer conexões) ou, contrariamente, se decompõe, desagregando e erodindo a coesão entre as partes. Quando encontramos um corpo que convém com o nosso, mesmo quando desconhecemos o que temos em comum, experimentamos a afetação da alegria, ao passo que, ao nos depararmos com um corpo que não convém com o nosso, somos afetados pela tristeza, que limita tanto o nosso poder de agir quanto o de padecer. A noção de corpo é assim evidenciada:

Um corpo pode ser qualquer coisa, pode ser um animal, pode ser um corpo sonoro, pode ser uma alma ou uma ideia, pode ser um corpus linguístico, pode ser um corpo social, uma coletividade. Entendemos por longitude de um corpo qualquer conjunto das relações de velocidade e de lentidão, de repouso e de movimento [...]. Entendemos por latitude o conjunto dos afetos que preenchem um corpo a cada momento, isto é, os estados intensivos de uma força anônima (força de existir, poder ser afetado). Estabelecemos assim a cartografia de um corpo. O conjunto das longitudes e das latitudes constitui a Natureza, o plano de imanência ou de consistência, sempre variável, e que não cessa de ser remanejado, composto, recomposto, pelos indivíduos e pelas coletividades (DELEUZE, 2002, p. 132-133).

Ao assumirmos essa compreensão deleuziana e transportá-la para o âmago de nosso objeto de estudo, poderemos compreender que ocupar o mesmo espaço institucional, a cátedra de ensino de Filosofia da Educação, não implica em ser afetado pelos mesmos elementos. Isso porque, além das diferenças constitutivas de cada corpo (a singularidade de cada professor), há uma extensa diversidade de outros corpos cujas reverberações são capazes de acarretar afetações alegres ou tristes: as relações com outras pessoas (professores, alunos, funcionários), com a própria disciplina Filosofia da Educação (concepções, temas e plano de ensino), ideias e estranhamentos. As relações entre os corpos podem ser como brisas quase imperceptíveis ou como rajadas intempestivas que fulminam e arrastam o chão sob nossos pés. E mesmo aqui, não há regras, hierarquias ou determinações: há quem aprecie brisas e quem prefira tempestades. As afetações são como cargas dinâmicas que pulsam em velocidades e ritmos diferenciados, sem regras padronizantes para determinar os encontros com aquilo que nos afeta. A única ressalva, é que para que haja encontros é preciso atentar para os limiares, nosso mínimo e nosso máximo, pois todo "encontro é preparado, tornado necessário pelos movimentos celestes e subterrâneos" (DELEUZE, 2002, p. 135).

É nesse sentido que nossa experimentação, no sentido deleuziano, não pode jamais pretender explicar (numa perspectiva exteriorizada, superior e pivotante) a prática de ensino dos colegas docentes, mas deve tentar implicar o próprio modo de ensino de Filosofia da Educação na e com as outras narrativas e experiências docentes que habitam o espaço institucional compartilhado desse território que chamamos de Filosofia da Educação nos cursos de Pedagogia e de outros cursos de licenciatura.

Diante do exposto até o momento, várias questões podem ser suscitadas a partir da filosofia prática deleuziana de inspiração espinosista. Lembrando que todos os corpos possuem em comum a extensão, o movimento e o repouso, podemos indagar: Quais são nossos limiares no âmbito do ensino da Filosofia da Educação? Que territórios visitamos, que distâncias percorremos e em qual velocidade? Inicialmente, quais foram as afetações que nos levaram a coabitar o espaço filosófico educacional no âmbito do ensino superior? Atualmente, nosso ofício de ensinar Filosofia da Educação está em movimento ou habita/repousa em algum corpo (teórico, temático)? Nossos encontros são permeados por paixões alegres ou 
tristes? E o que fazemos a respeito: buscamos promover os encontros alegres ou nos sujeitamos aos tristes? Em relação a esta última indagação, consideramos que a noção de encontro deve ser assumida de forma análoga àquela da acepção deleuziana de acontecimento, visto que ambas exigem de nós uma atitude. Explicamos a seguir essa similaridade.

Um acontecimento só pode ser considerado como tal, quando o assumimos como nossos, ou seja, quando deixamos de tentar nos esquivar, o que significa "não ser indigno daquilo que nos acontece" (DELEUZE, 2011, p.151). Isso implica em deixar de colocar a culpa de nossas feridas nos outros, abdicando de ressentimentos e aceitando estoicamente, o que nos acontece. É preciso "querer o acontecimento".

Que haja em todo acontecimento minha infelicidade, mas também um esplendor e um brilho que seca a infelicidade e que faz com que, desejado, o acontecimento se efetue em sua ponta mais estreitada, sob o corte de uma operação [...]. O brilho, o esplendor do acontecimento, é o sentido. $\mathrm{O}$ acontecimento não é o que acontece (acidente), ele é no que acontece o puro expresso que nos dá sinal e nos espera. [...] Não se pode dizer nada mais, nunca se disse nada mais: tornarse digno daquilo que nos ocorre, por conseguinte, querer capturar o acontecimento, tornar-se o filho de seus próprios acontecimentos e por aí renascer [...] (DELEUZE, 2011, p. 152).

O acontecimento é uma ferida: algo que marca profundamente nosso corpo e que não podemos ignorar, embora seja possível tentar fazê-lo por algum tempo. O acontecimento não é o que nos acontece, mas a nossa relação pessoal com o que nos acontece. Certas coisas, ideias e condições, embora já existam previamente, para que sejam tomadas como acontecimentos precisam ser assumidas como nossas. Desse modo, compreendemos que todo acontecimento é duplo, pois enquanto uma parte dele se realiza em nós, a efetuação, a outra parte somente será concretizada se houver de nossa parte a contraefetuação. À luz do acontecimento, mudamos nosso modo de pensar e conectamos passado e futuro num só momento, de modo que o tempo não é mais regido por Cronos, mas por Aión.

Em todo acontecimento existe realmente o momento presente da efetuação, aquele em que o acontecimento se encarna em um estado de coisas, um indivíduo, uma pessoa, aquele que designamos dizendo: eis aí, o momento chegou; e o futuro e o passado do acontecimento não se julgam senão em função deste presente definitivo, do ponto de vista daquele que o encarna. Mas há, de outro lado, o futuro e o passado do acontecimento tornado em si mesmo, que esquiva todo presente, porque ele é livre das limitações de um estado de coisas, sendo impessoal e pré-individual, neutro, nem geral, nem particular, eventum tantum. ...; ou melhor, que não há outro presente além daquele do instante móvel que o representa: sempre desdobrado em passado-futuro, formando o que é preciso chamar de contra-efetuação (DELEUZE, 2011, p. 154).

Particularmente, essa passagem é bastante significativa porque me leva a interrogar: o que fizemos a respeito daquilo que foi feito de nós? Sim, porque um acontecimento é sempre um duplo. Existe uma parte do acontecimento que se realiza no momento de sua ocorrência e uma parte que não pode ser realizada ou cumprida, exceto por nós que dele padecemos. Vimos que Deleuze (2011) chama esses dois componentes do acontecimento de efetuação e contra-efetuação. Assim, quando ele sugere que devemos estoicamente ser dignos daquilo que nos acontece, isso significa que um acontecimento não é um evento isolado, mas algo que possui duas concretizações, sendo que a última delas, só pode ser completada por nós.

Aqui, retomamos nossa aproximação entre as noções de encontro e acontecimento. Em ambas persiste um traço de duplicidade. $\mathrm{O}$ acontecimento só se realizará plenamente quando sua efetuação for completada pela contra-efetuação. Por sua vez, o encontro passional necessita de um movimento racional que resulte na compreensão das paixões que nos afetam. Esse esforço (conatus) ativo persistiria contra as forças externas que tendem a nos jogar de um lado para ou outro aleatoriamente, mediante impulsos, emoções, sentimentos e ideias inadequadas que enfraquecem nossa potência de padecer e de pensar. Aqui, não se trata de tentar subjugar a paixão através da razão, mas de mostrar a diferença entre os efeitos deletérios das paixões sem razão (maus encontros) e os efeitos salutares das paixões coordenadas pela razão (bons encontros). Esses bons encontros ou encontros alegres resultam de uma ação decorrente de uma compreensão do próprio agente:

E quanto mais deliberada for a minha decisão, mais responsável serei. A razão, a qual me dá uma clara concepção do que eu faço, faz que eu seja a causa disso. E é isso, em termos gerais, que Espinosa quer dizer por ação - um efeito que resulta de uma ideia que o concebe claramente. [...] Mas a cada ideia na mente corresponde uma modificação no corpo. [...] E quanto mais adequada é a ideia, mais a causa é interna ao agente - tanto mais ela pertence ao conatus que o define. Num sentido muito real, portanto, a adequação de ideias significa potência. A pessoa racional é aquela que sempre se esforça para aumentar essa potência, para mudar a paixão em ação e para assegurar a si mesma a alegria, a independência e a serenidade, que são as verdadeiras marcas da liberdade (SCRUTON, 2000, p. 35). 
Para Espinosa mente e corpo não são separados, mas constituem dois aspectos de uma mesma coisa, de modo que toda mudança que ocorre na potência corporal, também é uma mudança que ocorre na potência mental e vice-versa. Existe uma influência recíproca entre ambas (DELEUZE, 2002). Por um lado, os ferimentos corporais (físicos e emocionais) têm seus equivalentes mentais na dor que reduz a potência do nosso pensamento. Por outro lado, quanto mais inadequado for o nosso entendimento sobre as coisas externas que nos afetam, mais elas afligirão e exercerão controle sobre nossos corpos. Essas corrupções paralelas levam a pessoa a ter uma compreensão defeituosa de si própria e do mundo. Tanto na concepção de Deleuze quanto na de Espinosa estamos, na condição de seres corporificados, sujeitos à afetação de forças externas e trancados com elas num mundo de relações. Nessa circunstância, a única atitude sábia é tentar selecionar encontros alegres para aumentar a nossa potência, fazendo com que algumas das coisas que acontecem conosco também sejam produzidas por nós (SCRUTON, 2000; MACHADO, 1990).

Diante do exposto, podemos continuar nossa exploração em torno das noções deleuzianas arriscando a especulação de que embora todos os acontecimentos sejam encontros, nem todo encontro é um acontecimento. Isso porque, em linhas gerais, nas suas respectivas completudes, os encontros são afetações e os acontecimentos são sentidos. Podemos afirmar que existe uma miríade de encontros, alegres ou tristes, que permeiam a nossa territorialidade do ensino de Filosofia da Educação. Todavia, nosso acontecimento atual é apenas um: nossa busca pelo sentido de se professor(a) de Filosofia da Educação.

A esse respeito, é interessante recordar a visão de Deleuze (1992, p. 177) acerca do exercício de dar aulas: "dá-se um curso sobre aquilo que se busca, mas não sobre o que se sabe". Tal afirmação subverte o senso comum segundo o qual lecionamos sobre aquilo que sabemos já que a educação seria uma forma de transmissão de conhecimentos e formatação de cultura. Na sua provocativa definição, a aula é tratada como um exercício de busca de sentido, algo que não se conserva estaticamente porque está sempre se renovando e se produzindo a cada nova relação estabelecida (LÓPEZ, 2008, p. 11). A cada aula, novos encontros são estabelecidos e toda preparação teórica prévia será atravessada por relações que podem constituir ou não um grande esforço de pensamento, pois os alunos não costumam ouvir tudo atentamente, mas cada um pega aquilo que lhe convém, aquilo que precisa ou que tem vontade, ou aquilo que podem aproveitar para alguma coisa (DELEUZE, 1992).

Desse modo, nos termos que expusemos até aqui, podemos considerar que toda experiência docente com a disciplina Filosofia da Educação propicia tanto encontros alegres quanto encontros tristes. Ao mesmo tempo em que podemos vivenciar circunstâncias na sala de aula (elogios, críticas, questionamentos, problemas, variações e ajustes) que aumentavam nossa potência de sermos afetados pela territorialidade filosófica educacional, fora da sala de aula também podemos passar por situações opressivas que nos impactem, sugerindo que não temos saberes suficientes para ministrar a referida disciplina. Esses choques podem nos abater por um determinado tempo.

Posteriormente, devemos nos dar conta do ensinamento deleuziano de que o excesso de saber mata a filosofia e que, o não filosófico completa aquilo que é filosófico, pois "a filosofia tinha necessidade, não só de uma compreensão filosófica, por conceitos, mas de uma compreensão não filosófica, a que opera por perceptos e afetos" (DELEUZE, 1992, p. 178). Assim, em vez de nos deixar deprimir pelos encontros tristes que acusam uma insuficiência filosófica na nossa formação pedagógica ou vice-versa, podemos ser inspirados a transformar nosso estranhamento, nossa sensação de estrangeiridade, em um problema a partir do qual pudéssemos pensar acerca do sentido de ser professor nesse território complexo que é uma aula atravessada por linhas filosóficas e educacionais. Em termos deleuzianos, a aula como forma de arte é assim descrita:

Para se aprender a arte de ensinar, arte de dar aulas, a que tipo de signos um professor tem que estar sensível? Obviamente, aos signos da matéria que ele ensina, mas não apenas a isso. A arte do magistério envolve sensibilidade aos saberes que os corpos dos alunos trazem para uma sala de aula e ao tempo cronológico que estabelece o horário dos encontros que configuram uma aula. Também sensibilidade aos humores dos alunos, ao espaço onde a aula se dá, aos recursos que possui para fazer funcionar a sua matéria, ao currículo que determina o que vai acontecer naquele curso, naquela disciplina, enfim, a "matéria" a ser aprendida. [...] Como uma aula pode ser arte, se tudo o que se faz durante seu acontecimento é discernir, identificar, representar? Todas as aulas estão repletas de afecções, percepções, sensações que não produzem afectos e muito menos criam perceptos. As instituições educacionais e salas de aula estão cheias de informações e opiniões que afugentam os devires da matéria. Uma aula só pode ser uma obra de arte com aquele professor que se confunde com a matéria, que deixa de ser o sujeito de um conhecimento e se torna o corpo pelo qual os devires da matéria deixam inundar os corpos daqueles que ali vieram aprender (ZORDAN, 2005, p. 264-265).

$\mathrm{Na}$ concepção deleuziana, existe somente três potências do pensamento: a filosofia, a arte e a ciência. Cada uma delas efetua uma experimentação do pensamento 
que é singular e complementar às demais, sendo que todas elas se opõem à opinião, o não pensamento que se limita a reproduzir aquilo que já foi pensado. A ciência traça um plano de referência e cria funções. A arte compõe um plano de composição e cria perceptos e afectos. A filosofia estabelece um plano de imanência e cria conceitos. Todas elas se entrecruzam e, cada uma de seu modo, não prometem a estabilidade da opinião consensual, mas constituem um convite para a experimentação do pensamento (DELEUZE; GUATTARI, 2010; DELEUZE, 1992).

Como o magistério é uma forma de arte, os elementos não filosóficos que interpenetram a aula são os perceptos e os afectos. Tais elementos não devem ser confundidos, respectivamente, com a percepção e afecção. A afecção é a ação de uma causa externa sobre o corpo e a percepção é a organização e interpretação racional das sensações. Em contrapartida, os perceptos, os afectos e o conceito são potências que, conforme a leitura deleuziana da ética espinosista são definidas como devires que possuem a força para se tornar algo novo. Para fins didáticos, Gallo (2012, p.96) simplifica a terminologia deleuziana e chama de sensibilização essa etapa na qual o professor em vez de impor um problema para os alunos pensarem, introduz um tema para afetá-los. Essa estratégia implica em possibilitar que os alunos vivenciem, sintam na pele, o problema filosófico a partir de elementos não filosóficos como a arte, a música, a literatura o cinema, etc.

A partir da composição desse material, podemos afirmar que nós, professores, precisamos viver afetivamente o ensino de Filosofia da Educação e não meramente executar o programa da disciplina. Isso significa vivenciar e não bloquear as circunstâncias, as distintas situações que surgirão no âmbito da aula e que poderão aumentar ou diminuir nossa potência de acordo com a peculiaridade alegre ou triste dos diferentes encontros. Na concepção de Tadeu (2002), trata-se de vislumbrar o que acontece aos corpos quando eles se reúnem em movimentos de mútua afetação. Não se trata de uma soma de corpos, mas de uma composição ou encontro norteada pela questão de saber quais encontros são bons ou maus, isto é, quais combinações aumentam ou diminuem nossa potência de agir. Para ele, no âmbito acadêmico, devemos constantemente nos perguntar se novas combinações "disto" com "aquilo" podem ser melhores do que outras composições precedentes. Melhores no sentido de evitar a todo custo os maus encontros e de multiplicar os bons encontros.

A questão que persiste aqui é como nós, professores de Filosofia da Educação, podemos buscar promover encontros alegres nesse plano de composição imprevisível que é a aula?. Mesmo considerando a preparação prévia dos elementos componentes da aula, a relativa constância da presença de seus agentes (professores e alunos) e a segmentaridade dura na qual a disciplina está inserida no âmbito de um curso acadêmico (plano de curso, currículo, curso, instituição etc.), não há como fechar e antecipar totalmente as suas possibilidades. Pois, assim como a vida, a aula possui uma dimensão inapreensível e com um potencial desterritorializador que irá se contrapor ao plano de organização das fronteiras estabelecidas. Nesse sentido, a proposta é retomar a linha deleuziana das três imagens filosóficas e tentar habitar a superfície:

[...] como advogam alguns filósofos antigos, estoicos e cínicos, há uma racionalidade inapreensível pela racionalidade humana e que não permite ao indivíduo conduzir completamente a sua vida como ele bem deseja ou delibera conscientemente, já que ele está sujeito a essa racionalidade outra, às vicissitudes do que se vive e ao acontecimento que lhe acomete. Nesses termos, viver a vida como obra de arte não significa apenas moldá-la segundo os traços deliberados do artista, mas também se dobrar às forças da matéria, às asperezas e rugosidades de sua superfície e àquilo que lhe escapa ao que está sendo moldado, reconhecendo aí um limite e esperando que daí emerja algo novo e outros modos de existência (PAGNI, 2012, p. 48).

A tentativa de promover no ensino de Filosofia da Educação uma habitação das rugosidades e asperezas da superfície implica numa retomada, no âmbito da atividade formativa, da atitude ética e do compromisso político postulado pelos filósofos antigos cínicos e estoicos (PAGNI, 2012). Essa constatação também se coaduna com a crítica espinosista de que nas sociedades constituídas, os homens renunciam de suas potências individuais em prol do fortalecimento do todo (Estado). Nessa condição, a abdicação das potências individuais resulta num consentimento em se deixarem dominar por afecções passivas comuns de esperança, segurança e temor em detrimento da afecção ativa do amor à liberdade (DELEUZE, 2002, p. 113). Desse modo, a própria noção de formação seria pervertida, na acepção filosófica deleuziana, de superfície: como algo que não se submete nem às alturas teóricas e nem às profundezas da técnica, mas faz emergir tudo na superfície da vida, o que pode levar a uma transformação de si mediante a criação de novos modos de existência (MOTA, 2013). Isso porque não haveria por parte dos professores uma tentativa de formar (no sentido de formatar, dar uma forma) as novas gerações, mas haveria um empenho ou esforço em "convidá-las a estarem abertas a essa possibilidade de fazer de sua existência uma obra e de viver a verdadeira vida, expondo-se aos choques, às mudanças e às rupturas que podem trazer com os atuais modos de vivê-la" (PAGNI, 2012, p.48). 
Nessa perspectiva, destacamos a percepção de Foucault (2013, p.315), segundo a qual "aquele que cuidava de si mesmo tinha que escolher dentre todas as coisas que se podem conhecer através do conhecimento científico apenas aquelas relativas a ele e importantes para a vida". Conforme nossa interpretação, essa atividade seletiva pode ser associada com a noção de bons encontros que Deleuze (2002) estabelece a partir da filosofia de Espinosa. Contudo, permanece a questão acerca do que devemos fazer para poder selecionar o que é bom e evitar o que é ruim para a própria vida, com base nos encontros que nos acontecem? A resposta, que nos força a pensar em nossa própria experiência, se reveste de uma importância maior para o nosso estudo, pois está relacionada ao fato de que a noção de cuidado de si possui sempre a necessidade de uma relação com o outro que é o mestre.

Pois o cuidado de si é, com efeito, algo que, como veremos, tem sempre necessidade de passar pela relação com um outro que é o mestre. Não se pode cuidar de si sem passar pelo mestre, não há cuidado de si sem a presença de um mestre. Porém, o que define a posição do mestre é que ele cuida do cuidado que aquele que ele guia pode ter de si mesmo. Diferentemente do médico ou do pai de família, ele não cuida do corpo nem dos bens. Diferentemente do professor, ele não cuida de ensinar aptidões e capacidades a quem ele guia, não procura ensiná-lo a falar nem a prevalecer sobre os outros, etc. O mestre é aquele que cuida do cuidado que o sujeito tem de si mesmo e que, no amor que tem pelo seu discípulo, encontra a possibilidade de cuidar do cuidado que o discípulo tem de si próprio (FOUCAULT, 2004, p. 55).

Nos termos expostos acima, é possível constatar que Foucault faz uma nítida oposição entre aquilo que faz um professor e um mestre. Em linhas gerais, enquanto o primeiro estaria ocupado com a tarefa da transmissão de saberes, o último estaria preocupado em garantir "as práticas da espiritualidade (ou as experiências de pensamento)" (MUCHAIL, 2011, p. 99).

Sendo assim, o modo de dobrar as forças ou buscar linhas de fuga em relação ao instituído seria criar outros modos de existência para promover mudanças efetivas que possam nos conduzir a encontros alegres, resultando num aumento da nossa potência para agir (DELEUZE; GUATTARI, 2007). Tal prática demanda o domínio, o controle sobre nós mesmos que pode se constituir através de exercícios ascépticos que estariam vinculado a preparação do indivíduo para constituição de sua paraskeué, que tem o sentido de equipar-se, preparar-se para os infortúnios da vida (FOUCAULT, 2012).

A paraskeué designa a preparação do indivíduo para a sua existência. Trata-se, portanto, não de uma formação que objetiva um futuro exercício profissional ou uma função social, mas de uma preparação em relação aos acontecimentos da vida (acidentes, infortúnios, reveses etc.) que podem ou não ocorrer. A paraskeué encerra tanto o sentido de equipar o indivíduo para tais adversidades, dotando-o com os recursos necessários (como se fossem uma armadura) para enfrentar os acontecimentos, quanto o sentido de ser um treinamento que visa propiciar um melhor desempenho no uso desses recursos no momento oportuno. Essa proposta seria uma alternativa às teorias da universalidade do sujeito porque na constituição de si, mesmo o sujeito estando enredado pelas relações de poder e saber, ele encontra formas de se subjetivar a partir das técnicas de si (FOUCAULT, 2012).

Somente podemos nos reinventar criando modos de subjetivação que, por sua vez, nos possibilitam resistir às forças que tentam nos assujeitar à fixação, sem a possibilidade de experimentação de si que nos conduziria a pensar e a transitar para encontros que nos potencializassem. Diferentemente do assujeitamento que provoca uma sensação de familiaridade, a subjetivação propicia um estranhamento a determinados padrões estabelecidos e leva a resistência em relação a essa familiaridade motivada pela sensação de liberdade.

\section{CONSIDERAÇõES FINAIS}

A perspectiva deleuziana concebe o próprio pensamento como um processo, um fluxo de movimento contínuo que é provocado por encontros agradáveis ou incômodos com objetos exteriores que se colocam diante de nós e nos forçam a pensar sobre os mesmos. Assim, quando buscamos estabelecer novas possibilidades conectivas a partir daquilo se apresenta diante de nós, damos continuidade ao fluxo a partir de novos encontros. Inversamente, quando obstruímos o fluxo, somos levados a pensar aquilo que já foi pensado previamente. E aquilo que nos faz pensar é o que encontramos e não aquilo que reconhecemos.

Um professor que adentra o território filosóficoeducacional e escolhe ou a Filosofia ou a Educação, como principal área norteadora de seu ensino, acaba incentivando seus alunos a fazerem o mesmo. Nessa situação, simplesmente escolher qualquer um dos lados significa aceitar de forma passiva e incontestável algo previamente estabelecido, ou seja, trata-se meramente de praticar a recognição, que irá adequar tudo à teoria vigente, sem deixar margem para a eclosão da novidade. Inversamente, na acepção deleuziana, uma aula não deve ser sobre algo que já sabemos, mas sobre aquilo que buscamos: não se trata de reconhecer, mas de buscar novos encontros. 
Considerando que a noção de bons encontros está relacionada à possibilidade de criação de novos modos de existência, é preciso atentar para o fato de que os encontros são preparados por movimentos celestes e subterrâneos. Das alturas teóricas, fazemos descer as ferramentas conceituais que necessitamos para exercitar o pensamento acerca das questões que fazemos emergir das profundezas que são forças constantes que impulsionam o pensar para um mergulho dentro do ethos cultural e da concretude da vida. Habitar a superfície é buscar novos modos de existência a partir daquilo que pegamos dos dois limiares, combinando-os sem hierarquias. Desse modo, tudo o que é preciso fazer é atentar para aquilo que nos afeta como corpos que se conectam. Tais conexões serão consideradas a partir desses dois limiares, alturas e profundezas, que não tem um lugar determinado, pois são somente pontos para norteamento: enquanto os encontros que aumentam nossa potência conectiva de afetar e ser afetado são considerados bons, os encontros que atuam inversamente são considerados maus.

A relação entre alturas e profundezas faz emergir novos modos de existência que se constituem como efeitos da superfície. Dessa experiência que implica em uma resistência aos modos de ver, sentir e pensar conforme os padrões ou modelos pré-estabelecidos podem surgir novos modos de subjetivação que não estão pautados somente na representação ao instituído, mas que abrem brechas para se pensar e praticar aquilo que nos afeta além do espaço acadêmico.

Por isso, a perspectiva deleuziana é complementada pela noção foucaultiana de cuidado de si, já que nessa acepção as teorias trazidas para a sala de aula, são apresentadas de maneira que se relacionem com o modo de vida dos alunos. Em relação a esse aspecto, em relação aos seus alunos, o professor de filosofia da educação também deve agregar o sentido foucaultiano de paraskeué, pois em decorrência das vicissitudes da vida, o indivíduo precisa estar preparado para os acontecimentos que acometerem a sua existência. Sem a preparação necessária para as adversidades, o indivíduo não seria capaz de realizar a contra-efetuação daquilo que a vida the propiciar. Dessa forma, a filosofia da educação como um bom encontro não contemplaria não apenas as questões relativas ao conhecimento, mas também as inquietações concernentes às atitudes cotidianas da vida, isto é, aos modos de existência.

\section{REFERÊNCIAS}

DELEUZE, Gilles; GUATTARI, Félix. Mil platôs: capitalismo e esquizofrenia. Aurélio Guerra Neto. São Paulo: Editora 34, 2007. v. 3.
DELEUZE, Gilles; GUATTARI, Félix. O que é a filosofia? Tradução Bento Prado Jr. e Alberto Alonso Muñoz. 3. ed. São Paulo: Editora 34, 2010.

DELEUZE, Gilles. Conversações. Tradução Peter Pál Pelbart. São Paulo: Editora 34, 1992.

DELEUZE, Gilles. Espinosa: filosofia prática. Tradução Daniel Lins. São Paulo: Escuta, 2002.

DELEUZE, Gilles. Lógica do sentido. Tradução Luiz Roberto Salinas Fortes. São Paulo: Perspectiva, 2011.

FOUCAULT, Michel. A hermenêutica do sujeito. Tradução Márcio Alves da Fonseca e Salma Tannus Muchail. São Paulo: Martins Fontes, 2004.

FOUCAULT, Michel. Ética, sexualidade e política. Tradução Elisa Monteiro e Inês Altran Dourado Barbosa. Rio de Janeiro: Forense Universitária, 2012.

FOUCAULT, Michel. Michel Foucault entrevistado por Hubert L. Dreyfus e Paul Rabinow. In: DREYFUS, Hubert L.; RABINOW, Paul. Michel Foucault, uma trajetória filosófica: para além do estruturalismo e da hermenêutica. Tradução Vera Portocarrero e Gilda Gomes Carneiro. Rio de Janeiro: Forense Universitária, 2013. p. 296-327.

FREITAS, Alexandre Simão de. Foucault e a educação: um caso de amor (não) correspondido? In: PAGNI, Pedro Ângelo; BUENO, Sinésio Ferraz; GELAMO, Rodrigo Peloso (Orgs.). Biopolítica, arte de viver e educação. São Paulo: Cultura Acadêmica, 2012. p. 51-73.

GALLO, Sílvio. Deleuze e a educação. Belo Horizonte: Autêntica, 2008.

GALLO, Sílvio. Metodologia do ensino de filosofia. Campinas, SP: Papirus, 2012.

KOHAN, Walter. Subjetivação, Educação e Filosofia. Perspectiva, Florianópolis, v. 18, n. 34, p. 143-158, jul./dez. 2000.

LÓPEZ, Maximiliano Valério. Acontecimento e experiência no trabalho filosófico com crianças. Belo Horizonte: Autêntica, 2008.

MACHADO, Roberto. Deleuze e a filosofia. Rio de Janeiro: Graal, 1990.

MOTA, Fernanda Antônia Barbosa da. O ensino da filosofia da educação como arte da superfície. Tese (Doutorado em Educação) - Universidade Federal do Piauí, Teresina, 2013.

MUCHAIL, Salma Tannus. Foucault, mestre do cuidado. São Paulo: Loyola, 2011.

PAGNI, Pedro Ângelo. Um lugar para a experiência e suas linguagens entre os saberes e as práticas escolares: pensar a infância e o acontecimento na práxis educativa. In: PAGNI, Pedro Ângelo; GELAMO, Rodrigo Peloso (Orgs.). Experiência, educação e contemporaneidade. São Paulo: Cultura Acadêmica, 2010. p. 15-34.

PAGNI, Pedro Ângelo. Entre a modernidade educacional e o modernismo: um ensaio sobre a possibilidade de uma Filosofia da Educação como arte da superfície. In: SEVERINO, A. J.; ALMEIDA, C. R. S.; LORIERI, M. A. (Orgs.). Perspectivas da Filosofia da Educação. São Paulo: Cortez, 2011. p. 150-166. 
PAGNI, Pedro Ângelo. Matizes filosófico-educacionais da formação humana e os desafios da arte de viver. In: PAGNI, Pedro Ângelo; BUENO, Sinésio Ferraz; GELAMO, Rodrigo Peloso (Orgs.). Biopolítica, arte de viver e educação. São Paulo: Cultura Acadêmica, 2012. p.35-50.

SCRUTON, Roger. Espinosa. São Paulo: Edunesp, 2000.

TADEU, Tomaz. A arte do encontro e da composição: Spinoza + currículo + Deleuze. Educação \& Realidade, Porto Alegre, v. 27, n. 2, p. 123-130, jul./dez. 2002.

TADEU, Thomaz; KOHAN, Walter. Apresentação - Dossiê "Entre Deleuze e a educação". In: Revista Educação e Sociedade, Campinas, v. 26, n. 93, p. 1171-1182, set./dez. 2005.
ZORDAN, Paola. Arte com Nietzsche e Deleuze. Educação \& Realidade, Porto Alegre, v.30, n.2, p.261-272, jul./dez. 2005.

Recebido em 11.12.2016

Aprovado em 28.06.2018

Endereço para correspondência:

Universidade Federal do Piauí (UFPI)

Centro de Ciências da Educação (CCE)

Departamento de Fundamentos da Educação (DEFE)

Campus Ministro Petrônio Portela, s/no

64040-730 Teresina, PI, Brasilí 